\title{
Potential Use of Benomyl for Control of Ergot (Claviceps africana) in Sorghum A-lines in Zimbabwe
}

\author{
D. E. Frederickson and K. Leuschner, SADC/ICRISAT, P.O. Box 776, Bulawayo, Zimbabwe
}

\begin{abstract}
Frederickson, D. E., and Leuschner, K. 1997. Potential use of benomyl for control of ergot (Claviceps africana) in sorghum A-lines in Zimbabwe. Plant Dis. 81:761-765.

In the absence of a successful practice for the control of ergot on sorghum A-lines (male-steriles) in Zimbabwe, two fungicides, Benlate and Thiram, were tested in greenhouse and field experiments. Fungicides were either applied to sorghum panicles singly, at concentrations of 0.1 or $0.2 \%$ a.i., or combined in mixtures at $0.1 \%$ a.i. each. Fungicides were applied before inoculation at heading or stigma exsertion, or after disease became visible. Treatment with either Benlate or Thiram was ineffective if applied when disease first became visible. A significant reduction in initial disease severity, rate of disease increase, and final disease severity was achieved with one application of Benlate at $0.2 \%$ a.i. at heading or stigma exsertion. At the concentrations tested Benlate and Thiram did not reduce seed-set in R- (restorer) lines.
\end{abstract}

Additional keywords: Sphacelia sorghi, sugary disease

Ergot of sorghum, caused by Claviceps africana Frederickson, Mantle \& de Milliano (6), is the major disease of A-lines, or the male-sterile parent, used in hybrid seed production in southern Africa $(2,4)$. The same pathogen was responsible for the sudden and widespread ergot outbreaks in Brazil in 1995 (20) and Queensland, Australia, in 1996 (21).

Ergot is an ovary replacement disease that creates two major problems. First, infection of A-line (male-sterile) ovaries by the ergot pathogen precludes normal seed-set or development; thus, infections are directly responsible for seed yield losses. Second, seeds developing adjacent to infected florets often become contaminated with the sugary, sphacelial honeydew, supporting growth of saprophytic surface molds. Such seeds are of poor quality (14) and are downgraded as such and, because of their stickiness, may be difficult to remove during harvesting (15).

Control of ergot in A-lines through the use of resistant cultivars is not feasible because resistance has been recognized only in sorghum varieties and landraces $(2,18,24)$. The resistance mechanism appears to hinge upon a rapid self-pollination response in these cultivars (8). Such a mechanism clearly has no application in an A-line, which is male-sterile by design.

Corresponding author: D. E. Frederickson

Current address of D. E. Frederickson: 32 Berrington Rd., Norwich, NR66PH, U.K.

Accepted for publication 25 March 1997.

Publication no. D-1997-0513-04R

(C) 1997 The American Phytopathological Society
The poor success of other strategies to control ergot, including routine practices such as crop rotation, deep plowing of field litter, and planting date, has been discussed in the extensive review of Bandyopadhyay et al. (3). Control through pollen-based management is difficult because of the overriding influence of climate on sorghum ergot development $(3,9,12,16,17)$.

Every 5 to 10 years in Zimbabwe, a severe ergot epiphytotic results in almost total seed loss (R. D. Swift and P. L. Hurrell, personal communication). Annual yield losses through direct replacement of seeds by ergot are estimated by hybrid producers (farmers) to reach $25 \%$; indirect losses by contamination from honeydew may be an extra 12 to $25 \%$ (J. A. Barry, R. D. Swift, and P. L. Hurrell, personal communication). To a hybrid seed producer with 40 to 60 ha recovering 4 to $5 \mathrm{t} / \mathrm{ha}$, seed losses of $25 \%$, discounting other inputs, represent as much as ZW\$100,000 (US\$ 13,000) in lost profit at 1993 grain prices. Even much smaller losses of $5 \%$ of 4 to $5 \mathrm{t} / \mathrm{ha}$ of expected yields give economic justification for control through the judicious use of fungicides (D. E. Frederickson, unpublished).

Fungicide control of ergot has been extensively investigated in India for the sorghum ergot pathogen $C$. sorghi. Thiophanate methyl, Thiram, Ziram, captafol, and Dithane-M45 sprayed twice increased yields of A-line seed from 1 to 4 t/ha $(1,10,13)$. Nagurajan and Saraswathi (19) concluded that systemic fungicides, including Benlate, had no effect on $C$. sorghi ergot in vitro or in the field situation. In contrast, with the more aggressive pathogen $C$. africana in South Africa, yields were increased following application of the systemic fungicides benomyl, bitertanol, carbendazim/flusilazol, CG169374, procymidone, propiconazol, terbuconazole, and triadimenol, but were still too small to give economical control (15).

Given the lack of alternatives, it was considered necessary to re-examine the potential use of fungicides in Zimbabwe for the economic control of ergot through only one application of fungicide.

\section{MATERIALS AND METHODS}

Greenhouse experiments. At heading (panicle emergence from boot), pots of the A-line ATx623 were organized into a randomized block design. Due to seed limitations there were only 2 replications. Each block consisted of 9 experimental units or treatments of 3 to 5 plants each. Treatments 1 to 4 consisted of 0.1 and $0.2 \%$ a.i. Thiram $(80 \%$ wettable powder, E. I. Du Pont de Nemours) or Benlate (50WP, E. I. Du Pont de Nemours) applied before infection or only after disease became evident; treatments 5 to 8 consisted of $0.2 \%$ a.i. Thiram or Benlate applied similarly; treatment 9 was a control consisting of no fungicide application. For treatments 1 to 4 , fungicides were sprayed to run-off at $50 \%$ panicle flowering and subsequently inoculated (5) with a suspension of $10^{6}$ conidia $/ \mathrm{ml}$. For treatments 5 to 8 , panicles were inoculated when flowering reached the panicle base but they were only sprayed to run-off with Benlate or Thiram when infections were evident, approximately 7 to 10 days later. The control panicles (treatment 9) were inoculated when flowering reached the panicle base.

From the time of first appearance of infections (sphacelia) disease severity (amount of panicle infected) was assessed on each infected head at 2- to 6-day intervals, as a percentage (experiment 1 ) or on a scale of 1 to 9 (experiment 2), where $1=$ no apparent infection and $9=100 \%$ infected.

Field experiments with A-lines. At Matopos and Henderson Research Stations in Zimbabwe, an area of approximately 45 by $80 \mathrm{~m}$ was sown with 7 row plots, each 4 $\mathrm{m}$ long, of a male-sterile A-line, ATx623, in early January 1993. Three replications were set up at Henderson, but a seed shortage (due to difficulties in generating pure A-line seed) meant that only two replications could be sown at Matopos. Matopos, south of Bulawayo, was chosen to represent a natural sorghum-growing area of low rainfall, whereas Henderson, north of Harare, was in a high rainfall area, more typical of a commercial farm location. The 
environment at Henderson favored profuse secondary conidiation and thus spread, but secondary conidiation was also common at Matopos (5). Plots were separated on all sides by 5 -m-wide plots of the tall maize hybrid R201 to minimize interplot interference. Fungicide treatments were $0.2 \%$ a.i. each of Benlate and Thiram, and $0.1 \%$ Benlate mixed with $0.1 \%$ Thiram. Panicles were sprayed to run-off with fungicides at late heading/early stigma exsertion (Henderson), more specifically at $50 \%$ heading or 50\% stigma exsertion (Matopos), or with the onset of infection (Henderson and Matopos). Fungicides were allowed to dry if inoculation was to follow immediately.

At the 50\%-stigma-exsertion stage, panicles of all treatments were sprayinoculated until run-off with a suspension of $10^{6}$ conidia $/ \mathrm{ml}$. Inoculation was repeated after 1 day. All spraying (inoculum or fungicides) was carried out using knapsack sprayers. Controls consisted of inoculated plots without any fungicide treatment.
Disease severity (percent of panicle infected) was assessed at Henderson at 13 and 42 days post-inoculation, and at Matopos at 7 and 21 days post-inoculation. Assessments were made on 35 panicles in control plots and 42 to 70 panicles in each treated plot.

Field experiments with R-lines. To be useful in hybrid production plots, the potential fungicide must not be toxic to the receptive stigma or ovary, nor gametocidal towards the pollen. This was tested at Matopos. In early January 1993, the R-line A964 was planted in 7-row plots of 4-m length, separated by 7 rows of 5-m-length maize plots. The randomized block design consisted of two replications of each of the following treatments: $0.2 \%$ a.i. Benlate or Thiram, or $0.1 \%$ each Benlate and Thiram in combination. Controls did not receive any chemical. Treatments were applied twice, once when approximately $15 \%$ of panicles were in anthesis, and again at $50 \%$ anthesis. Treatments were always applied

Table 1. Final ergot severities in the sorghum A-line ATx623 following Benlate or Thiram application to panicles in greenhouse experiment 1

\begin{tabular}{lccc}
\hline Time of spray $^{\mathbf{a}}$ & Fungicide & \% a.i. & Mean \% ergot severity \\
\hline Post & Thiram & 0.1 & 42.5 \\
Control & $\ldots$ & $\ldots$ & 39.6 \\
Post & Benlate & 0.1 & 31.0 \\
Post & Thiram & 0.2 & 16.0 \\
Post & Benlate & 0.2 & 13.0 \\
Pre & Thiram & 0.1 & 9.5 \\
Pre & Thiram & 0.2 & 2.0 \\
Pre & Benlate & 0.1 & 0.5 \\
Pre & Benlate & 0.1 & 0.2 \\
\hline
\end{tabular}

${ }^{a}$ Pre means that the chemicals were applied to panicles before inoculation with ergot; post means that the chemicals were applied with the first indication of infection.

b Treatments were significantly different at $P<0.01$.

Table 2. Orthogonal contrasts between treatments in greenhouse experiments 1 and 2 and Henderson and Matopos field experiments

\begin{tabular}{lcccc}
\hline Orthogonal contrast $^{\mathrm{a}}$ & Greenhouse 1 $^{\text {Pre vs. control }}$ & Greenhouse 2 & Henderson & Matopos \\
\hline Pre vs. post & $0.01^{\mathrm{b}}$ & 0.01 & 0.01 & $\ldots$ \\
Post vs. control & 0.01 & 0.01 & 0.01 & $\ldots$ \\
Heading vs. control & $\mathrm{NS}$ & 0.05 & $\mathrm{NS}$ & $\mathrm{NS}$ \\
Stigmas vs. control & $\ldots$ & $\ldots$ & $\ldots$ & 0.01 \\
Heading vs. stigmas & $\ldots$ & $\ldots$ & $\ldots$ & 0.01 \\
\hline
\end{tabular}

${ }^{\mathrm{a}}$ Pre = fungicide application to panicles before inoculation with ergot; post $=$ application with the first indication of infection; heading $=$ application at heading; stigma = application at stigma exsertion; control $=$ no fungicide application .

b Significance: $P=0.01, P=0.05$, and NS $=$ not significant. as spray until run-off early in the morning to coincide with anther dehiscence and pollination. After 6 weeks, 35 panicles per plot were harvested randomly, and the number of sessile florets with and without seed were counted to estimate percent seed set. Bulked seed from all panicles in a plot were used to obtain 1,000-grain mass.

Statistical analysis. Analysis of variance and orthogonal contrasts were performed using the general linear models procedure of SAS (SAS Institute, Cary, NC).

\section{RESULTS}

Greenhouse experiments. Temporal measurements of disease severity in ex-

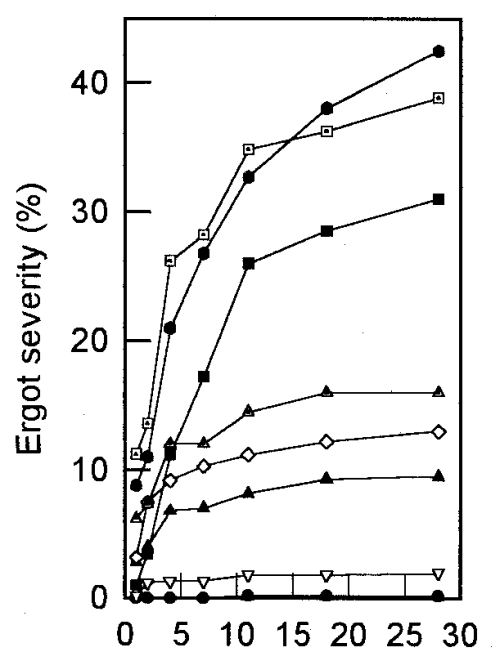

Time after inoculation (days)

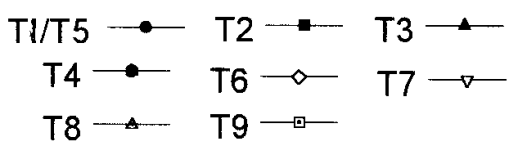

Fig. 1. Effect of Benlate (Be) and Thiram (T), sprayed before (pre) or after (post) inoculation, on the rate of increase of ergot severity in the sorghum A-line ATx623 in greenhouse experiment 1 . Treatments are: $\mathrm{T} 1,0.1 \%$ a.i. Be pre; $\mathrm{T} 2,0.1 \%$ a.i. Be post; T3, $0.1 \%$ a.i. T pre; T4, $0.1 \%$ a.i. $\mathrm{T}$ post; $\mathrm{T} 5,0.2 \%$ a.i. Be pre; $\mathrm{T} 6,0.2 \%$ a.i. Be post; $\mathrm{T} 7,0.2 \%$ a.i. T pre; $\mathrm{T} 8,0.2 \%$ a.i. $\mathrm{T}$ post; T9, untreated control.

Table 3. Least significant difference contrasts between treatment means in greenhouse experiment 1 at $P=0.01$ and $P=0.05$ probability levels

\begin{tabular}{|c|c|c|c|c|c|c|c|c|c|}
\hline Treatments ${ }^{\mathrm{a}}$ & 1 & 2 & 3 & 4 & 5 & 6 & 7 & 8 & 9 \\
\hline$\overline{1}$ & & & & & & & & & \\
\hline 2 & 0.01 & & & & & & & & \\
\hline 3 & $\mathrm{NS}^{\mathrm{b}}$ & 0.05 & 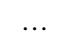 & & & & & & \\
\hline 4 & 0.01 & NS & 0.01 & & & & & & \\
\hline 5 & NS & 0.01 & NS & 0.01 & $\ldots$ & & & & \\
\hline 6 & NS & NS & NS & 0.01 & NS & $\ldots$ & & & \\
\hline 7 & NS & 0.01 & NS & 0.01 & NS & NS & $\ldots$ & & \\
\hline 8 & NS & NS & NS & 0.01 & NS & NS & NS & & \\
\hline 9 & 0.01 & NS & 0.01 & NS & 0.01 & 0.05 & 0.01 & 0.05 & $\ldots$ \\
\hline
\end{tabular}

${ }^{a}$ Treatments 1 and $2=0.1 \%$ a.i. Benlate; 3 and $4=0.1 \%$ a.i. Thiram; 5 and $6=0.2 \%$ a.i. Benlate; 7 and $8=0.2 \%$ a.i. Thiram. Treatments $1,3,5$, and 7 were applied before inoculation with ergot and 2, 4, 6, and 8 after inoculation with ergot. Treatment 9 was the control.

${ }^{\mathrm{b}} \mathrm{NS}=$ not significantly different. 
periment 1 (Fig. 1) showed that some fungicide treatments significantly reduced the rate of increase of ergot severity and final severity (Table 1) compared to the nontreatment comparisons (Tables 2 and 3) clarified that all preventative sprays, whether 0.1 or $0.2 \%$ Benlate or Thiram, reduced disease significantly over the control. Once disease was evident, application of the higher concentrations of $0.2 \%$ Bentreated control. Orthogonal contrasts and

late or Thiram gave better results than no spraying (Table 3 ).

The same general trend was evident from experiment 2 (Tables 2, 4, and 5) where again all preventative treatments, irrespective of chemical or dose, reduced disease significantly compared to the control. However, curative sprays were ineffective, probably because higher initial inoculum resulted in higher initial severities.

Table 4. Ergot severities in the sorghum A-line ATx623 following Benlate or Thiram application to panicles in greenhouse experiment 2

\begin{tabular}{lccc}
\hline Time of spray $^{\mathbf{a}}$ & Fungicide & \% a.i. & Ergot severity $^{\mathbf{b}}$ \\
\hline Control & $\ldots$ & $\ldots$ & $5.3(0.4)$ \\
Post & Thiram & 0.2 & $7.6(0.7)$ \\
Post & Thiram & 0.1 & $6.3(0.6)$ \\
Post & Benlate & 0.2 & $6.2(0.6)$ \\
Post & Benlate & 0.1 & $5.5(0.6)$ \\
Pre & Thiram & 0.2 & $5.2(0.6)$ \\
Pre & Thiram & 0.1 & $4.2(0.6)$ \\
Pre & Benlate & 0.1 & $3.2(0.6)$ \\
Pre & Benlate & 0.2 & $0.3(0.6)$ \\
\hline
\end{tabular}

${ }^{a}$ Pre means that the chemicals were applied to panicles before inoculation with ergot; post means that the chemicals were applied with the first indication of infection.

${ }^{\text {b }}$ Ergot severity evaluated on a 1 to 9 scale where $1=<1 \%, 2=1$ to $5 \%, 3=6$ to $10 \%, 4=11$ to $20 \%, 5=21$ to $40 \%, 6=41$ to $60 \%, 7=61$ to $80 \%, 8=81$ to $90 \%$, and $9=91$ to $100 \%$. The figure in parentheses is the standard error of the mean. Treatments were significantly different at $P<0.01$.

Table 5. Least significant difference contrasts between treatment means in greenhouse experiment 2 at $P=0.01$ and $P=0.05$ probability levels

\begin{tabular}{cccccccccc}
\hline Treatments $^{\mathbf{a}}$ & $\mathbf{1}$ & $\mathbf{2}$ & $\mathbf{3}$ & $\mathbf{4}$ & $\mathbf{5}$ & $\mathbf{6}$ & $\mathbf{7}$ & $\mathbf{8}$ & $\mathbf{9}$ \\
\hline 1 & $\ldots$ & & & & & & & & \\
2 & 0.01 & $\ldots$ & & & & & & \\
3 & $\mathrm{NS}^{\mathrm{b}}$ & $\mathrm{NS}$ & $\ldots$ & & & & & \\
4 & 0.01 & NS & 0.01 & $\ldots$ & & & & & \\
5 & 0.01 & 0.01 & 0.01 & 0.01 & $\ldots$ & & & & \\
6 & 0.01 & NS & 0.05 & NS & 0.01 & $\ldots$ & & & \\
7 & 0.05 & NS & NS & NS & 0.01 & NS & $\ldots$ & $\ldots$ & \\
8 & 0.01 & 0.05 & 0.01 & NS & 0.01 & NS & 0.01 & $\ldots$ \\
9 & 0.01 & NS & NS & NS & 0.01 & NS & NS & 0.01 & $\ldots$
\end{tabular}

${ }^{a}$ Treatments 1 and $2=0.1 \%$ a.i. Benlate; 3 and $4=0.1 \%$ a.i. Thiram; 5 and $6=0.2 \%$ a.i. Benlate; 7 and $8=0.2 \%$ a.i. Thiram. Treatments $1,3,5$, and 7 were applied before inoculation with ergot and $2,4,6$, and 8 after inoculation with ergot. Treatment 9 was the control.

${ }^{\mathrm{b}} \mathrm{NS}=$ not significantly different.

Table 6. Final ergot severities in the sorghum A-line, ATx623, following Benlate or Thiram application to panicles at Henderson and Matopos

\begin{tabular}{lrcc} 
& & \multicolumn{2}{c}{ Mean \% severity $^{\mathbf{c}}$} \\
\cline { 3 - 4 } Time of spray $^{\mathbf{a}}$ & Fungicide $^{\mathbf{b}}$ & Henderson & Matopos \\
\cline { 3 - 4 } Pre & Benlate & 26.8 & $\ldots$ \\
Pre & Thiram & 79.9 & $\ldots$ \\
Pre & Benlate \& Thiram & 27.2 & $\ldots$ \\
Post & Benlate & 84.7 & 62.2 \\
Post & Thiram & 82.5 & 60.2 \\
Post & Benlate \& Thiram & 78.2 & 55.5 \\
Control & $\ldots$ & 81.6 & 60.5 \\
Heading & Benlate & $\ldots$ & 13.9 \\
Stigma & Benlate & $\ldots$ & 7.9 \\
Heading & Thiram & $\ldots$ & 51.3 \\
Stigma & Thiram & $\ldots$ & 37.7 \\
Heading & Benlate \& Thiram & $\ldots$ & 16.7 \\
Stigma & Benlate \& Thiram & $\ldots$ & 12.9 \\
\hline
\end{tabular}

${ }^{\text {a }}$ Pre $=$ fungicide application to panicles before inoculation with ergot; post $=$ application with the first indication of infection; heading = application at heading; stigma = application at stigma exsertion; control $=$ no fungicide application

${ }^{\mathrm{b}}$ Fungicides were used singly at $0.2 \%$ a.i., or in combination at $0.1 \%$ a.i.

${ }^{\mathrm{c}}$ Treatments were significantly different at $P<0.01$.
A-line field experiments. Orthogonal contrasts of treatments at Henderson and Matopos indicated that preventative treatments reduced disease significantly compared to the controls (Tables 2, 6, and 7) but curative treatments were ineffective. Comparisons between pairs of treatments at Henderson showed that preventative treatments involving Benlate were most effective. At Matopos, where preventative treatments were further subdivided, applications of Benlate at heading or stigma exsertion were equally effective. Initial disease severities and rates of disease increase were both reduced by the Benlate preventative treatments at Henderson (Fig. 2) and Matopos (Fig. 3). At Matopos, Thiram applications were more effective at stigma exsertion, as might be expected of a nonsystemic fungicide, but Thiram did not reduce disease compared to the control at Henderson.

R-line field experiments. No adverse effects of fungicide application were visible on the R-line, since seed-set and 1,000grain mass were unaffected by the treatments (Table 8).

\section{DISCUSSION}

The current absence of alternative control methods for sorghum ergot in A-lines justifies the judicious use of fungicides. Our studies suggest good potential for

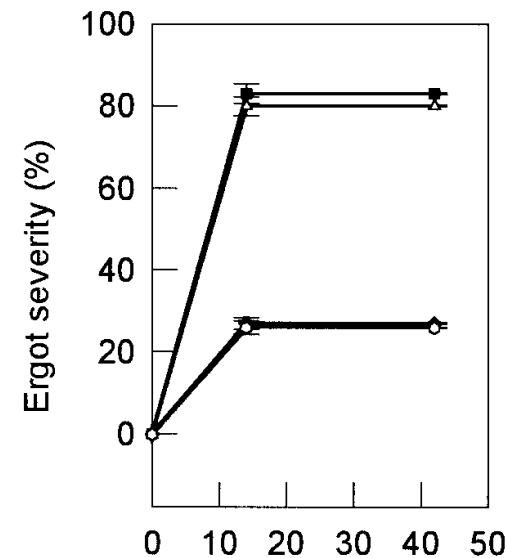

Time after inoculation (days)

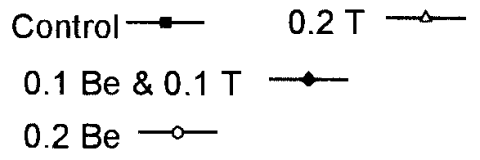

Fig. 2. Effect of Benlate (Be) and Thiram (T) application on ergot severity in the sorghum Aline ATx623 at Henderson. Control refers to untreated plots; fungicides were applied at late heading/early stigma emergence at $0.2 \%$ a.i. (singly) or $0.1 \%$ a.i. each (in combination). Bar indicates $\mathrm{SE}$ of the mean of three replications; when no bar, SE was less than the size of the symbol used. The treatments applied once disease became evident were not significantly different from the control and are omitted for clarity. 
control of ergot through minimal preventative application of the systemic fungicide Benlate.

A single Benlate application of $0.2 \%$ a.i. at heading or stigma exsertion gave good field control of ergot even after direct challenge with a high inoculum concentration in environments conducive to disease (Figs. 2 and 3). Benlate was highly effective at Henderson, an environment that supports profuse honeydew exudation and secondary sporulation on panicles, factors of prime consequence for secondary spread $(5,7)$. Despite the high initial ergot severity and rate of disease increase in the control, disease was much reduced by Benlate preventative treatments. In contrast, Thiram could not contain the disease increase resulting from the initial outbreaks at Henderson, although slight control was achieved at Matopos. Fungicides were ineffective as curative agents, corroborating the data of McLaren (15). The discrepancy in results for fungicides applied as curatives in greenhouse experiments 1, compared to experiment 2 and both field experiments, may have arisen because of the higher initial severities in the latter three cases, as well as the field environments (wind, rain, higher relative humidity) being far more conducive to disease development.

Experiments in India recognized the utility of two or three sprays of Ziram, Zineb, or other contact fungicides for ergot control $(1,10,13)$. In Zimbabwe, one application of Benlate was able to substantially reduce initial and final disease severities. In these field experiments with A-lines, pathogen challenge was continual from lateral spread of inoculum between heads in the same plot or from auto-infection. Yet, a single spray of Benlate still proved effective over time. Its efficacy was probably largely due to the lowering of inoculum pressure (primary and secondary inoculum) in treated plots. In the A-lines of hybrid production plots, initial inoculum and initial severities are usually much less than in our experiments, but lateral disease spread from such small, initial sources can still be rapid and massive in unpollinated panicles $(5,7)$. Benlate demonstrated good control over potentially large disease severity increases from direct challenge with a large initial inoculum. In addition, pollination and seed-set processes were not disturbed by application of Benlate or Thiram at the concentrations used. Coupled with the reduction of disease through pollination, Benlate would be expected to

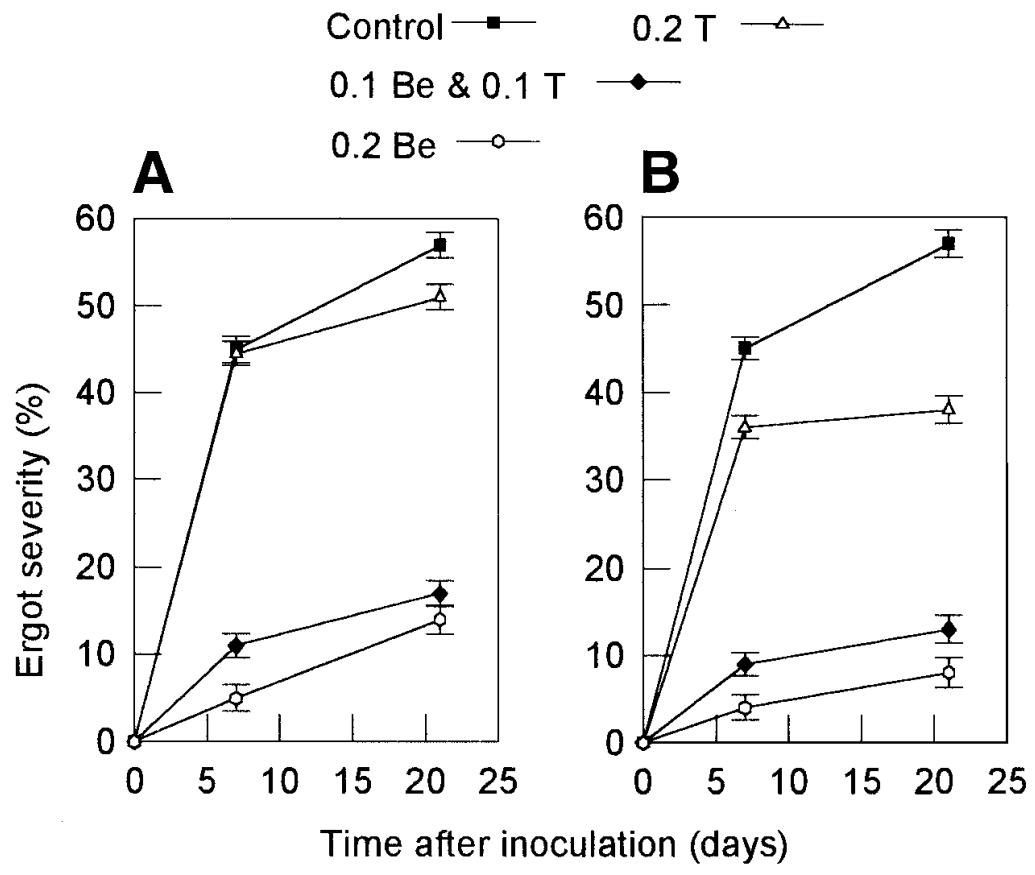

Fig. 3. Effect of Benlate (Be) and Thiram (T) application before stigma exsertion (A) and at 50\% stigma exsertion (B) on changes in ergot severity with time in the sorghum A-line ATx623 at Matopos. Fungicides were applied at concentrations of $0.2 \%$ a.i. singly or $0.1 \%$ a.i. each in combination. Bar indicates SE of the mean of two replications. The treatments applied once disease became evident were not significantly different from the control and are omitted for clarity.

Table 8. Seed-set and 1,000-grain mass of sorghum seed following treatment of the R-line A964 with Benlate or Thiram in the field

\begin{tabular}{lcc}
\hline Treatment $^{\mathbf{a}}$ & Seed-set $(\boldsymbol{\%})$ & $\mathbf{1 , 0 0 0}$ grain mass $(\mathbf{g})$ \\
\hline Benlate + Thiram & $98.8^{\mathrm{b}} \mathrm{a}$ & $11.7 \mathrm{a}$ \\
Thiram & $99.0 \mathrm{a}$ & $10.9 \mathrm{a}$ \\
Benlate & $98.8 \mathrm{a}$ & $13.3 \mathrm{a}$ \\
Control & $98.7 \mathrm{a}$ & $11.3 \mathrm{a}$ \\
\hline
\end{tabular}

a Treatments, applied by spraying panicles twice at $15 \%$ and $50 \%$ anthesis, were Benlate and Thiram ( $0.1 \%$ a.i. each), Thiram ( $0.2 \%$ a.i.), Benlate ( $0.2 \%$ a.i.), and control (none).

b Means in each column with the same letter are not significantly different, according to Duncan's multiple range test $(P<0.05)$.

Table 7. Comparison of treatment (Trt) means for Henderson (lower left of ellipses) and Matopos (above right of ellipses) field experiments at $P=0.01$ and $P=0.05$ significance levels

\begin{tabular}{|c|c|c|c|c|c|c|c|c|c|c|}
\hline $\operatorname{Trt}^{\mathrm{a}}$ & 1 & 2 & 3 & 4 & 5 & 6 & 7 & 8 & 9 & 10 \\
\hline 1 & $\ldots$ & NS & 0.01 & 0.01 & NS & NS & 0.01 & 0.01 & 0.01 & 0.01 \\
\hline 2 & 0.01 & $\ldots$ & 0.01 & 0.01 & NS & NS & 0.01 & 0.01 & 0.01 & 0.01 \\
\hline 3 & NS & 0.01 & $\ldots$ & 0.01 & 0.01 & 0.01 & NS & NS & NS & 0.05 \\
\hline 4 & 0.01 & NS & 0.01 & $\ldots$ & 0.01 & 0.01 & 0.01 & 0.01 & 0.01 & 0.01 \\
\hline 5 & 0.01 & NS & 0.01 & NS & $\ldots$ & NS & 0.01 & 0.01 & 0.01 & 0.01 \\
\hline 6 & 0.01 & NS & 0.01 & NS & NS & $\ldots$ & 0.01 & 0.01 & 0.01 & 0.01 \\
\hline 7 & 0.01 & NS & 0.01 & NS & NS & NS & $\ldots$ & NS & NS & NS \\
\hline 8 & & & & & & & & $\ldots$ & NS & NS \\
\hline 9 & & & & & & & & & $\ldots$ & NS \\
\hline & idersc & & & & & & & & & Matopos \\
\hline
\end{tabular}

${ }^{\mathrm{a}}$ Henderson treatments: $1=$ Benlate pre, $2=$ Thiram pre, $3=$ Benlate and Thiram pre, $4=$ Benlate post, $5=$ Thiram post, $6=$ Benlate and Thiram post, $9=$ control. Matopos treatments: $1=$ Benlate at heading, $2=$ Benlate at stigma exsertion, $3=$ Thiram at heading, $4=$ Thiram at stigma exsertion, $5=$ Benlate and Thiram at heading, $6=$ Benlate and Thiram at stigma exsertion, $7=$ Benlate post, $8=$ Thiram post, $9=$ Benlate and Thiram post, $10=$ control. Pre, heading, and stigma exsertion means that fungicides were applied before inoculation with ergot; post means they were applied with the first disease symptoms. Fungicides were used singly at $0.2 \%$ a.i. or in combination at $0.1 \%$ a.i. 
give excellent control in hybrid production plots.

Efficacy of Benlate at heading facilitates early application by the farmer, ensuring protection to emerging stigmas.

With expected yields of 4 to $5 \mathrm{t} / \mathrm{ha}$, grain losses of only 5\% would, at 1993 chemical and grain prices, justify the use of Benlate (ZW\$70/US\$9 per $\mathrm{kg}$ Benlate and ZW\$65/US\$8.5 per $\mathrm{kg}$ grain). In South Africa, McLaren found the use of chemical control uneconomical (15) but average yields were only 1 to 3 t/ha. Even with such reduced yields in Zimbabwe, the use of Benlate would still be financially justifiable if ergot was responsible for seed losses of $8 \%$; losses are frequently higher.

In the rush to protect vulnerable A-lines in Australia, South America, and the United States with fungicides, one further important consideration for the future must be the prevention of the development of resistance to Benlate and other benzimidazoles, for which polycyclic pathogens like ergot are notorious $(11,22,23)$. Fungicide mixtures of benzimidazoles with a triazole have demonstrated prolonged efficacy compared to the benzimidazole alone $(22,23)$ and could also delay the occurrence of such a problem with sorghum ergot.

\section{ACKNOWLEDGMENTS}

D. Frederickson thanks SADC/ICRISAT for support of this research through a post-doctoral research fellowship. We thank the sorghum hybrid farmers (J. A. Barry, R. D. Swift, and P. L. Hurrell) for helpful discussions and on-farm visits.

\section{LITERATURE CITED}

1. Anahosur, K. H. 1979. Chemical control of ergot of sorghum. Indian Phytopathol. 32:487-489.

2. Bandyopadhyay, R. 1992. Sorghum ergot. Pages 235-244 in: Sorghum and Millet Dis- eases: A Second World Review. W. A. J. De Milliano, R. A. Frederiksen, and G. D. Bengston, eds. Patancheru, A. P. 502 324, India: ICRISAT.

3. Bandyopadhyay, R., Frederickson, D. E., McLaren, N. W. \& Odvody, G. N. 1996. Ergot, a global threat to sorghum. Int. Sorghum Millet News1. 37:1-32.

4. de Milliano, W. A. J. 1992. Sorghum diseases in Southern Africa. Pages 9-19 in: Sorghum and Millet Diseases: A Second World Review. W. A. J. De Milliano, R. A. Frederiksen, and G. D. Bengston, eds. Patancheru, A. P. 502 324, India: ICRISAT.

5. Frederickson, D. E., Mantle, P. G., and de Milliano, W. A. J. 1989. Secondary conidiation of Sphacelia sorghi on sorghum, a novel factor in the epidemiology of sorghum ergot disease. Mycol. Res. 93:497-502.

6. Frederickson, D. E., Mantle, P. G., and de Milliano, W. A. J. 1991. Claviceps africana sp. nov; the distinctive ergot pathogen of sorghum in Africa. Mycol. Res. 95:1101-1107.

7. Frederickson, D. E., Mantle, P. G., and de Milliano, W. A. J. 1993. Windborne spread of ergot disease (Claviceps africana) in sorghum A-lines in Africa. Plant Pathol. 42:368-377.

8. Frederickson, D. E., Mantle, P. G., and de Milliano, W. A. J. 1994. Susceptibility to ergot in Zimbabwe of sorghums that remained uninfected in their native climates in Ethiopia and Rwanda. Plant Pathol. 43:27-32.

9. Futrell, M. C., and Webster, O. J. 1966. Host range and epidemiology of the sorghum ergot organism. Plant Dis. Rep. 50:828-831.

10. Gangadharan, K., Subramanian, N., Kandaswamy, T. K., and Sundarum, N. V. 1976. Control of sugary disease of sorghum. Madras Agric. J. 63:413-414.

11. Georgopoulos, S. G. 1987. The Development of fungicide resistance. Pages 239-251 in: Populations of Plant Pathogens: Their Dynamics and Genetics. BSPP. M. S. Wolfe and C. E. Caten, eds. Blackwell Scientific Publications.

12. Hulluka, M. 1982. Diseases of sorghum at some locations in Ethiopia. Ethiopian J. Agric. Sci. 4:45-53

13. Lakshmanan, P., Chandrasekaran, A., and Palanisamy, S. 1986. Chemical control of sugary disease of sorghum. Sorghum Newsletter 29:81.

14. McLaren, N. W. 1993. Effect of sugary disease exudates on germination, seedling development and predisposition to seedling diseases of sorghum (Sorghum bicolor). S. Afr J. Plant Soil 10:12-16.

15. McLaren, N. W. 1994. Efficacy of systemic fungicides and timing of preventative sprays in the control of sugary disease of grain sorghum (Sorghum bicolor). S. Afr. J. Plant Soil 11:30-33.

16. McLaren, N. W., and Wehner, F. C. 1990. Relationship between climatic variables during early flowering of sorghum and the incidence of sugary disease caused by Sphacelia sorghi. Journal Phytopathol. 130:82-88.

17. Molefe, T. L. 1975. Occurrence of ergot on sorghum in Botswana. Plant Dis. Rep 59:751-753.

18. Musabyimana, T., Sehene, C., and Bandyopadhyay, R. 1995. Ergot resistance in sorghum in relation to plant flowering, inoculation technique and disease development. Plant Pathol. 44:109-115.

19. Nagurajan, K., and Saraswathi, V. 1971. Effect of systemic fungicides on the sugary disease organism Sphacelia sorghi McRae. Sorghum Newsletter 14:41.

20. Reis, E. M., Mantle, P. G., and Hassan, H. A. G. 1996. First report in the Americas of sorghum ergot disease, caused by a pathogen diagnosed as Claviceps africana. Plant Dis. 80:463.

21. Ryley, M. J., Alcorn, J. L., Kochman, J. K., Kong, G. A., and Thompson, S. M. (1996) Ergot on Sorghum spp. in Australia. Australas. Plant Pathol. 25:214.

22. Skylakis, G. 1987. Changes in the composition of pathogen populations caused by resistance to fungicides. Pages 227-237 in: Populations of Plant Pathogens: Their Dynamics and Genetics. BSPP. M. S. Wolfe and C. E. Caten, eds. Blackwell Scientific Publications, Oxford, U.K.

23. Staub, T., and Sozzi, D. 1984. Fungicide resistance. Plant Dis. 68:1026-1031.

24. Tegegne, G., Bandyopadhyay, R., Mulatu, T., and Kebede, Y. 1994. Screening for ergot resistance in sorghum. Plant Dis. 78:873-876. 